\title{
Effects of $\mathrm{ZnCl}_{2}$ on the Distribution of Aldehydes and Ketones in Bio-oils from Catalytic Pyrolysis of Different Biomass
}

\author{
Bo-Zheng Li, ${ }^{\text {a }}$ Dong-Mei Bi, ${ }^{\mathrm{a}, *}$ Qing Dong, ${ }^{\mathrm{b}}$ Yong-Jun Li, ${ }^{\mathrm{a}}$ Ya-Ya Liu, ${ }^{\mathrm{a}}$ and \\ Fu-Peng Huang a
}

Bio-oil can serve as an alternative fuel source or resource to extract high value-added chemicals. This paper focuses on the effect of six types of biomass (rape straw, corn straw, walnut shell, chestnut shell, camphor wood, and pine wood) and $\mathrm{ZnCl}_{2}$ catalyst on the bio-oil yield and chemicals in the bio-oil, including aldehydes, ketones, and four high-value chemicals (1-hydroxy-2-butanone, propionaldehyde, 5-HMF, 2(5H)furanon). The results showed that the yields of bio-oil decreased when the $\mathrm{ZnCl}_{2}$ was the catalyst. The $\mathrm{ZnCl}_{2}$ promoted the production of aldehydes and ketones. The higher contents of aldehydes and ketones were obtained from camphor and pine wood, at $58.9 \mathrm{wt} \%$ and $42.0 \mathrm{wt} \%$, respectively. The $\mathrm{ZnCl}_{2}$ catalyst exhibited an active influence on the production of 1 hydroxy-2-butanone, propionaldehyde, 5-HMF, and 2(5H)-furanon. Compared with the non-catalytic pyrolysis, the content of 1-hydroxy-2butanone and $2(5 \mathrm{H})$-furanone in bio-oil increased by $936 \%$ and $612 \%$, respectively. The contents of propionaldehyde and 5-HMF in catalytic biooil were the highest from rape straw and increased by $193 \%$ and $86 \%$, respectively.

Keywords: Pyrolysis; Biomass; $\mathrm{ZnCl}_{2}$; Aldehydes; Ketones; High-value chemicals

Contact information: a: School of Agricultural Engineering and Food Science, Shandong University of Technology, Zibo, Box 255000, China; b: School of Life Science and Food Engineering, Huaiyin Institute of Technology, Huaian, 223003, China; *Corresponding author: dongmei070719@163.com

\section{INTRODUCTION}

Currently, fossil energy is the primary energy resource in the world (Knaggs et al. 2015). However, it will inevitably be depleted due to its continual uses. In addition, the combustion and usage of fossil fuels results in the emission of noxious greenhouse gases, including $\mathrm{CO}_{2}$, NOx, and sulfides (Sovacool et al. 2016; Zhou and Feng 2017). In contrast, biomass is a promising alternative to fossil fuel because of its renewable and carbon-neutral nature. Biomass can be used as a feedstock to produce various environmentally friendly materials, such as bio-asphalt (Zelelew et al. 2013), hydrophobic agents (Penmetsa and Steele 2012), and adsorbents (Li et al. 2017). Many preceding studies have focused on biooil through the incorporation of biomass pyrolysis technology (Wang et al. 2015). Bio-oil can be used as an engine fuel (Chwist et al. 2017), environmentally friendly binder (Hernando et al. 2019; Zabelkin et al. 2019), and organic chemical resource (Sharma et al. 2015). The utilization of biomass could lessen the extent of the greenhouse effect and reduce the presence of acid rain (Kan et al. 2012; Günther et al. 2015; Krivtcova et al. 2015).

Organic chemicals in bio-oil produced from biomass can reduce the cost of 
traditional chemicals and enhance the development of green environmentally friendly synthesis methods (Arevalo-Gallegos et al. 2017). High value-added chemicals (1hydroxy-2-butanone, propionaldehyde, 5-hydroxymethylfurfural (5-HMF), and 2 (5H)furanone) that are extracted from bio-oil can be mainly used as adhesives, food additives (Laino et al. 2012), preservatives (Magdalena et al. 2018), fine chemicals (Li et al. 2013), and fuel additives (Climent et al. 2014). The production of these chemicals requires expensive catalysts and strict reaction conditions of traditional methods, which would increase the production cost (Shen et al. 2015; Wang et al. 2019; Ye et al. 2019). Catalytic pyrolysis of biomass is a new technology for producing high value-added chemicals, in which the bio-oil can be used as the substrate. The chemical categories in bio-oil from catalytic pyrolysis mainly are sugars, acids, aldehydes, ketones, phenols, and lipids (Kabir and Hameed 2017; Bi et al. 2019). It has many advantages, such as gentle conversion conditions, low energy and cost inputs, higher yield, and selectivity of high-value chemicals.

Many high-value chemicals can be produced from biomass. For example, 1hydroxy-2-butanone $(\$ 111 / \mathrm{g}$, purity: $98 \%, 2019)$ is an important intermediate for synthesizing the anti-tuberculosis drug ethambutol. Paine et al. (2008) showed that levoglucosan was mainly produced from pyrolysis of cellulose. Zheng et al. (2016) and Lédé (2012) studied the mechanism of cellulose pyrolysis and found that 1-hydroxy-2butanone was mainly formed by the dehydration and decarboxylation of cellulose. Propionaldehyde $(\$ 19 / \mathrm{g}$, purity: $97 \%, 2019)$ is widely used as a raw material for synthetic resins, rubber promoters, etc. Propionaldehyde can be produced through the cracking/ dehydration of light oxides during the pyrolysis of biomass (Brech et al. 2016). 5-HMF (\$34/g, purity: 97\%, 2019) and its secondary derivatives, which are excellent substitutes for petroleum fuels, were important intermediates for synthesizing liquid alkanes (Ito et al. 2016). 5-HMF can be used as a raw material for medicine and pesticides. 5-HMF has been mainly formed from the cracking, acetal, and dehydration reaction of cellulose and hemicellulose (Bai et al. 2014). 2(5H)-furanone (\$18/g, purity: 98\%, 2019) has high biological activities; hence, it is widely used for antibacterial, anti-inflammatory, antiviral, and anti-cancer applications. In addition, $2(5 \mathrm{H})$-furanone has been shown to be a suitable starting point to synthesize medicinal and industrial products in recent years ( $\mathrm{Li}$ et al. 2016; Rossi et al. 2017).

Ketones are also a high-value chemical in bio-oil. Lazzari et al. (2016) found that the highest yield of chemicals in bio-oil were mainly in the form of ketones (34 wt\%), which were obtained from the pyrolysis of mango residues. $2(5 \mathrm{H})$-Furanone accounted for the highest proportion of ketone content $(9.4 \mathrm{wt} \%)$ in the bio-oil. Based on this finding, various catalysts have been found to play significant roles on the bio-oil yield and highvalue chemicals content (Li et al. 2018; Hemando et al. 2019; Liu et al. 2019). $\mathrm{ZnCl}_{2}$ is an inexpensive and abundant type of catalyst. It has been shown that the pyrolysis of poplar, corn cob, and cellulose can be enhanced by $\mathrm{ZnCl}_{2}$ at a lower temperature (Lu et al. 2011). This is because the cracking of holocellulose and the depolymerization of lignin are promoted, while the activation energy of impregnated wood is decreased by $\mathrm{ZnCl}_{2}$ (Néstor et al. 2016). Hence, it seems that $\mathrm{ZnCl}_{2}$ could be an effective catalyst to promote the cracking of cellulose and hemicellulose into high-value chemicals.

In this study, $\mathrm{ZnCl}_{2}$ was used as the catalyst during the pyrolysis process of biomass. Six types of biomass (rape straw, corn straw, walnut shell, chestnut shell, camphor wood, and pine wood) were used as feedstock. The main purposes of this study were to investigate the effects of $\mathrm{ZnCl}_{2}$ catalyst on the yield of bio-oil and the content of 
high-value chemicals (1-hydroxy-2-butanone, propionaldehyde, 5-HMF, and 2(5H)furanone) from pyrolysis of various biomass feedstock. This study, which aimed to analyze pyrolysis oil containing high-value chemicals, can be of great importance for improving the utilized value of biomass and exploring alternatives to fossil fuels.

\section{EXPERIMENTAL}

\section{Materials}

The raw materials used in this work were obtained from different regions in China. Specifically, rapeseed straw was harvested from Suzhou City (China), corn straw and pine were harvested from Zibo City (China), chestnut shell was harvested from Qingzhou City (China), and camphor wood was harvested from Shangrao City (China). All materials were pre-dried, pulverized, and screened before utilization. The particle size ranged from 0.22 to $0.38 \mathrm{~mm}$. The main components of the six biomasses (cellulose, hemicellulose, and lignin) were determined by the Van Soest measurement method (Rutkowski, 2011). The elemental analysis of biomass was performed using an elemental analyzer (EA3000; EuroVector, Milan, Italy). The proximate analysis of biomass was conducted in a muffle furnace (SX2-2.5-12; Jintanliangyou, Changchou, China). The content of the components is shown in Fig. 1. The elemental analysis and proximate analysis results of samples are shown in Table 1.

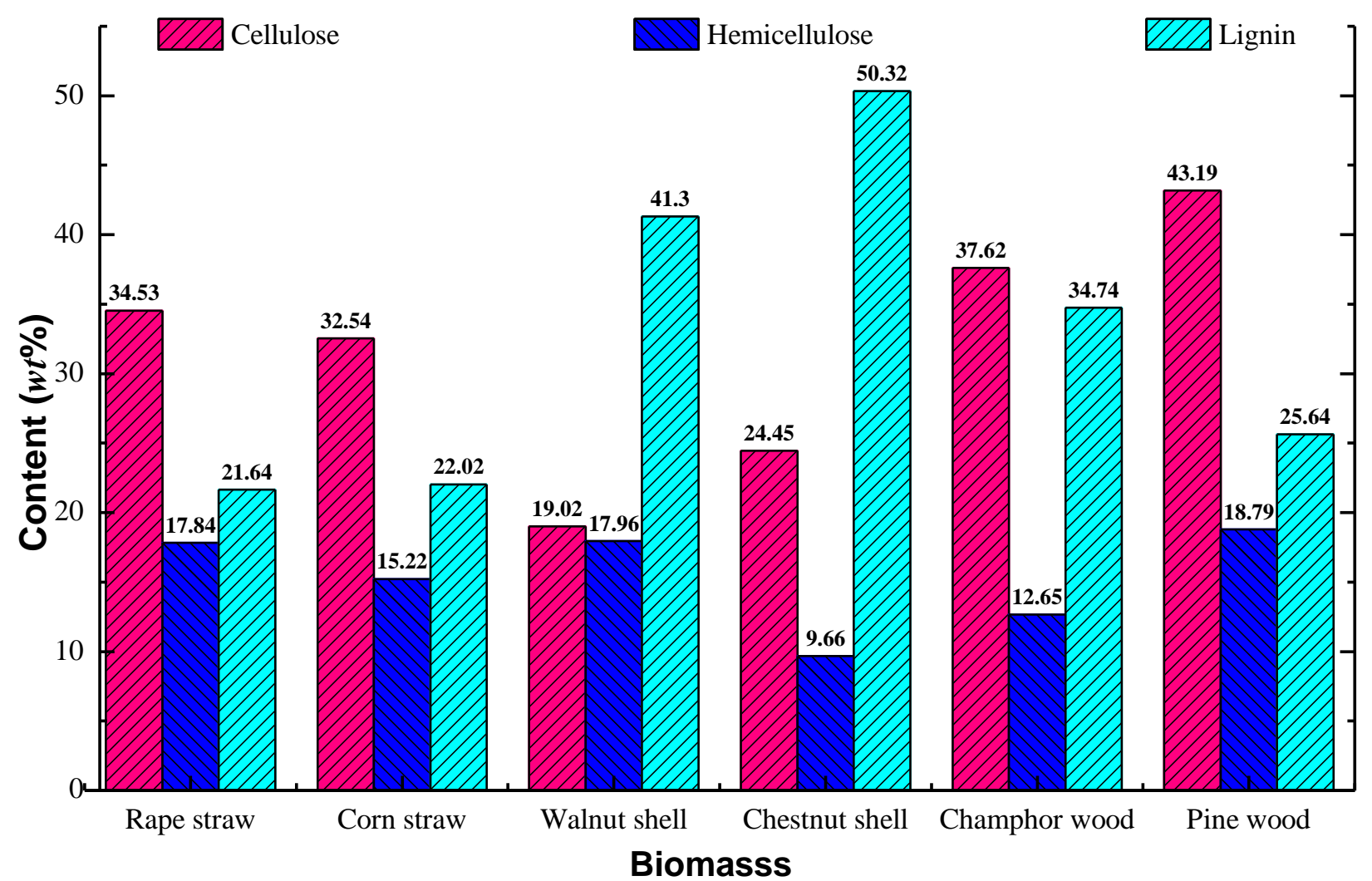

Fig. 1. Cellulose, hemicellulose, and lignin content for different types of biomass 
Table 1. Proximate Analysis and Elemental Analysis Results of the Materials

\begin{tabular}{|c|c|c|c|c|c|c|}
\hline \multirow{2}{*}{ Material } & \multicolumn{3}{|c|}{ Elemental Analysis (\%) } & \multicolumn{3}{c|}{ Proximate Analysis (\%) } \\
\cline { 2 - 7 } & $\mathrm{C}$ & $\mathrm{H}$ & $\mathrm{O}$ & $\begin{array}{c}\text { Fixed } \\
\text { Carbon }\end{array}$ & Volatiles & Ash \\
\hline Rape straw & 48.52 & 5.74 & 45.74 & 15.27 & 79.18 & 5.55 \\
\hline Corn straw & 47.46 & 5.78 & 46.76 & 12.26 & 80.59 & 7.15 \\
\hline Walnut shell & 48.23 & 5.72 & 46.05 & 18.39 & 81.21 & 0.4 \\
\hline Chestnut shell & 48.10 & 5.82 & 46.08 & 28.08 & 70.84 & 1.08 \\
\hline Camphor wood & 53.16 & 6.12 & 40.72 & 13.35 & 86.14 & 0.51 \\
\hline Pine wood & 50.16 & 5.77 & 44.07 & 17.06 & 80.07 & 2.87 \\
\hline
\end{tabular}

\section{Experimental Methods}

The pyrolysis equipment used in this study was a SKZ-4-B constant temperature horizontal tube furnace reactor. Figure 2 shows the schematic diagram of the reactor. The reactor consisted of a pyrolyzer and a condensing device. Prior to conducting experiments, nitrogen gas was introduced for a period of time to ensure an oxygen-limited environment. Non-catalytic pyrolysis and catalytic pyrolysis were conducted on the reactor. As for catalytic pyrolysis, $\mathrm{ZnCl}_{2}$ was chosen as catalyst, and it was mixed with raw materials at the mass ratio of $1: 1$. Once the temperature of the furnace reached $500{ }^{\circ} \mathrm{C}$, the biomass was quickly placed into the reactor. During the pyrolysis, the raw materials were placed in a porcelain boat, which was then covered by quartz wool with a thickness of $0.5 \mathrm{~mm}$. The $\mathrm{ZnCl}_{2}$ catalyst was then placed on the quartz wool to ensure the catalytic influenced the pyrolysis process. The flow rate of nitrogen was set at a rate of $60 \mathrm{~L} / \mathrm{h}$. The retention time was 5 min because the reaction finished within $1 \mathrm{~s}$. After the pyrolysis experiments completed, the gas product was condensed by a condenser at $-10{ }^{\circ} \mathrm{C}$, and bio-oil was subsequently collected. The residue solid was bio-char. The catalysts can be effectively separated from raw materials using the quartz wool with good gas permeability. The catalyst can remain catalytic activity and be used for reusing after regeneration.

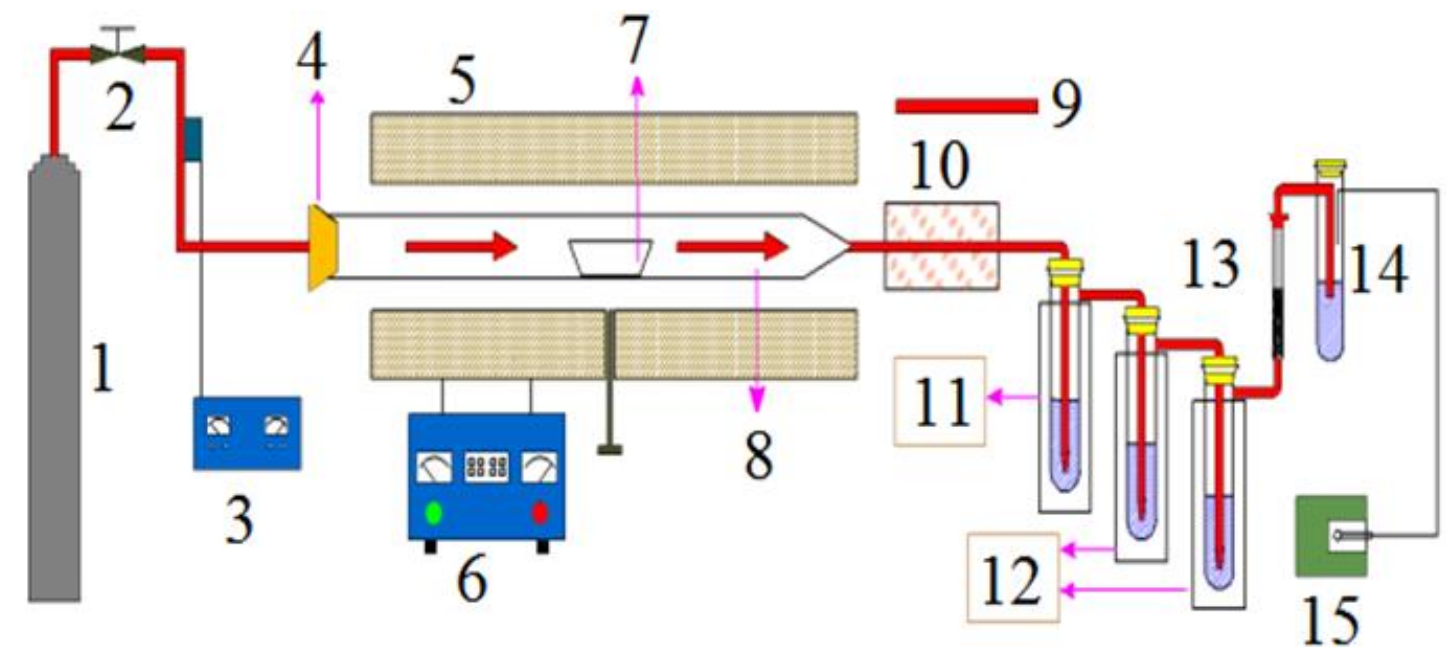

Fig. 2. Schematic diagram of the biomass pyrolysis horizontal tube furnace reaction: $1 . \mathrm{N}_{2}$ bottle; 2. Valve; 3. Mass flow meter; 4. Rubber plug; 5 . Horizontal tube furnace; 6 . Control box; 7. Porcelain boat; 8. High temperature resistant quartz tube; 9. Rubber tube; 10. Insulated rock wool; 11. First stage condensation; 12. Cold trap; 13. Low temperature thermostat; 14. Gas drying device; 15. Air bag 


\section{Products of Pyrolysis}

The yields of products can be calculated by the followed equations.

$$
\text { Bio-oil yield: } Y_{\text {oil }}: Y_{\text {oil }}=\frac{M_{\text {oil }}}{M} \times 100 \%
$$

where $M_{o i l}$ and $M$ represent the weights (g) of bio-oil and biomass.

$$
\text { Bio-char yield, } Y_{\text {char }}: Y_{\text {char }}=\frac{M_{\text {char }}}{M} \times 100 \%
$$

where $M_{c h a r}$ and $M$ represent the weights (g) of bio-char and biomass.

$$
\text { Bio-gas yield, } Y_{\text {gas }}: \quad Y_{\text {gas }}=100-Y_{\text {oil }}-Y_{\text {char }}
$$

Two typical ketones (1-hydroxy-2-butanone and 2(5H)-furanone) and two typical aldehydes (propionaldehyde and 5-HMF) were selected to analyze. The content of chemicals in bio-oil was determined by gas chromatography-mass spectrometry (GC-MS), (5972N; Agilent, Santa Clara, CA, USA) equipped with a Rtx-5 capillary column (30 $\mathrm{m} \times$ $0.25 \mathrm{~mm} \times 0.25 \mu \mathrm{m})$. The carrier gas was He with high purity $(>99.99 \%)$. The split ratio was 30:1, the injection volume was $0.2 \mu \mathrm{L}$. and the gasification temperature was $280{ }^{\circ} \mathrm{C}$. The temperature procedure was set to increase from room temperature to $240{ }^{\circ} \mathrm{C}$ with a heating rate of $5^{\circ} \mathrm{C} / \mathrm{min}$, and then held for $5 \mathrm{~min}$. The ionization mode was EI. The electron bombardment energy was $70 \mathrm{eV}$. The temperature of ion source and the interface were set at $240{ }^{\circ} \mathrm{C}$ and $250{ }^{\circ} \mathrm{C}$, respectively.

\section{RESULTS AND DISCUSSION}

\section{Products Yields and Distribution}

The yields of bio-oil, bio-gas, and bio-char with or without $\mathrm{ZnCl}_{2}$ catalyst are shown in Fig. 3. The highest bio-oil yield was from camphor wood (45.8 wt \%), while the lowest bio-oil was from chestnut shell $(35.5 \mathrm{wt} \%)$. Compared with that, lower yields (44.1 wt $\%$ and $42.5 \mathrm{wt} \%$ ) were obtained by pine wood and rape straw, respectively. The varied yields produced from the raw materials could be impacted by the varied content of components (Qu et al. 2011; Wang et al. 2016). In this case, walnut shell had a higher biooil yield (42.4 wt\%) than those of corn straw (40.8 wt \%) and chestnut shell (35.5 wt \%), which was because walnut shell had a higher content of vegetable oil that was mainly converted into bio-oil. The highest volatiles were obtained in camphor wood (Table 1), which might be the cause for the higher yield of biochar. In the control groups, the highest bio-char yield (38.8 wt\%) was obtained from camphor wood.

The bio-oil and bio-char yields from catalytic pyrolysis are depicted in Fig. 3. The highest bio-oil yield was from corn straw (40.4 wt\%), while the lowest bio-oil was from camphor wood $(32.5 \mathrm{wt} \%)$. These results showed that bio-oil yields from catalytic pyrolysis were definitely lower than that from non-catalytic pyrolysis. It can be concluded that the $\mathrm{ZnCl}_{2}$ catalyst exhibited a negative impact on the yields of bio-oil. The bio-oil yields of camphor wood and pine wood noticeably decreased $29.0 \%$ and $14.6 \%$, respectively, which was attributed to the fact that the conversion of cellulose and hemicellulose into small gas molecules was promoted, while the decomposition of lignin was inhibited (Stefanidis et al. 2014). The results were consistent with a previous study from $\mathrm{Hu}$ et al. (2017) who used $\mathrm{ZnCl}_{2}$ as catalyst during pyrolysis of corn straw lignin and 
found that the production of bio-oil was inhibited, while that of bio-char and bio-gas was promoted. The bio-oil yields of camphor wood and pine wood were higher compared to that of rape straw, corn straw, walnut shell, and chestnut shell. As shown in Fig. 1, the contents of cellulose and lignin in camphor wood and pine wood were higher than those in rape straw, corn straw, walnut shell, and chestnut shell. Hence, higher content of cellulose and lignin resulted in greater reduction in bio-oil yield. Meanwhile, there was no noticeable influence of $\mathrm{ZnCl}_{2}$ catalyst on corn straw-derived bio-oil yield, which only decreased 1.03 $\mathrm{wt} \%$. However, the $\mathrm{ZnCl}_{2}$ catalyst showed a positive effect on the production of bio-char. To be specific, the increase of bio-char yields from camphor wood and pine wood were relatively lower than that from chestnut shell, corn straw, walnut shell, and rape straw.

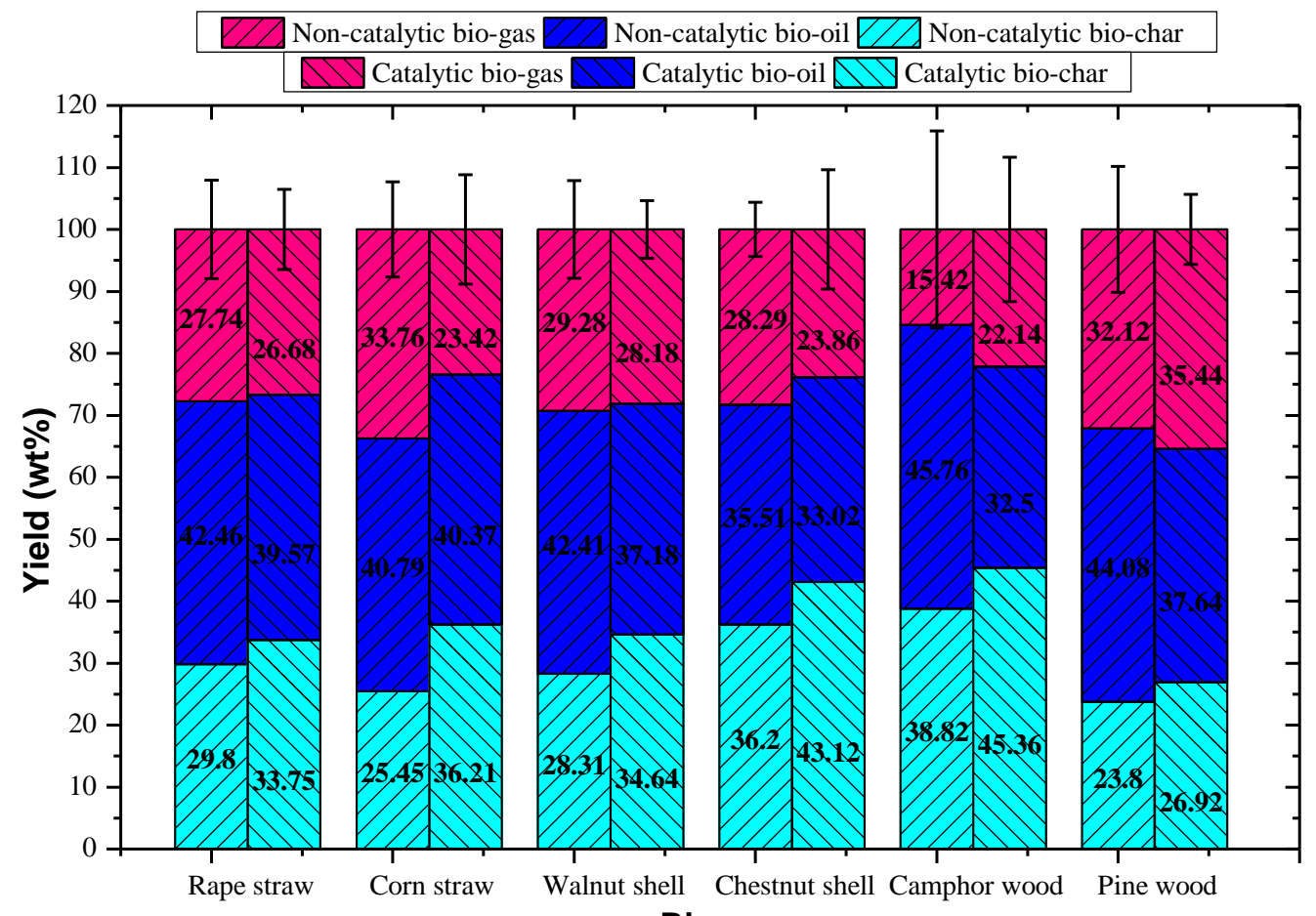

Biomass

Fig. 3. Pyrolysis products yields from six types of biomass

\section{Content of Aldehydes and Ketones in Bio-oil}

The content of aldehydes and ketones in bio-oils is shown in Fig. 4. For noncatalytic pyrolysis of six types of biomass, the content of aldehydes and ketones in bio-oil from rape straw and corn straw was $29.7 \mathrm{wt} \%$ and $24.1 \mathrm{wt} \%$, respectively. This was because the two biomass feedstocks had higher content of holocellulose (cellulose and hemicellulose) that were the main resources of aldehydes and ketones. During the process of pyrolysis, aldehydes and ketones can be converted from the cracking of cellulose and hemicellulose (Zhang et al. 2018). When the $\mathrm{ZnCl}_{2}$ catalyst was added, the contents of aldehydes and ketones in the catalytic bio-oil of six types of biomass increased. Specifically, a higher content was obtained from camphor wood and pine wood (58.9 wt\% and $42.0 \mathrm{wt} \%$ ), which was mainly caused by the promotion of the $\mathrm{ZnCl}_{2}$ catalyst in the interaction of lignin with cellulose. Hence, camphor wood and pine wood would be the optimum feedstock to produce aldehydes and ketones when applying $\mathrm{ZnCl}_{2}$ catalyst during the process of pyrolysis. 


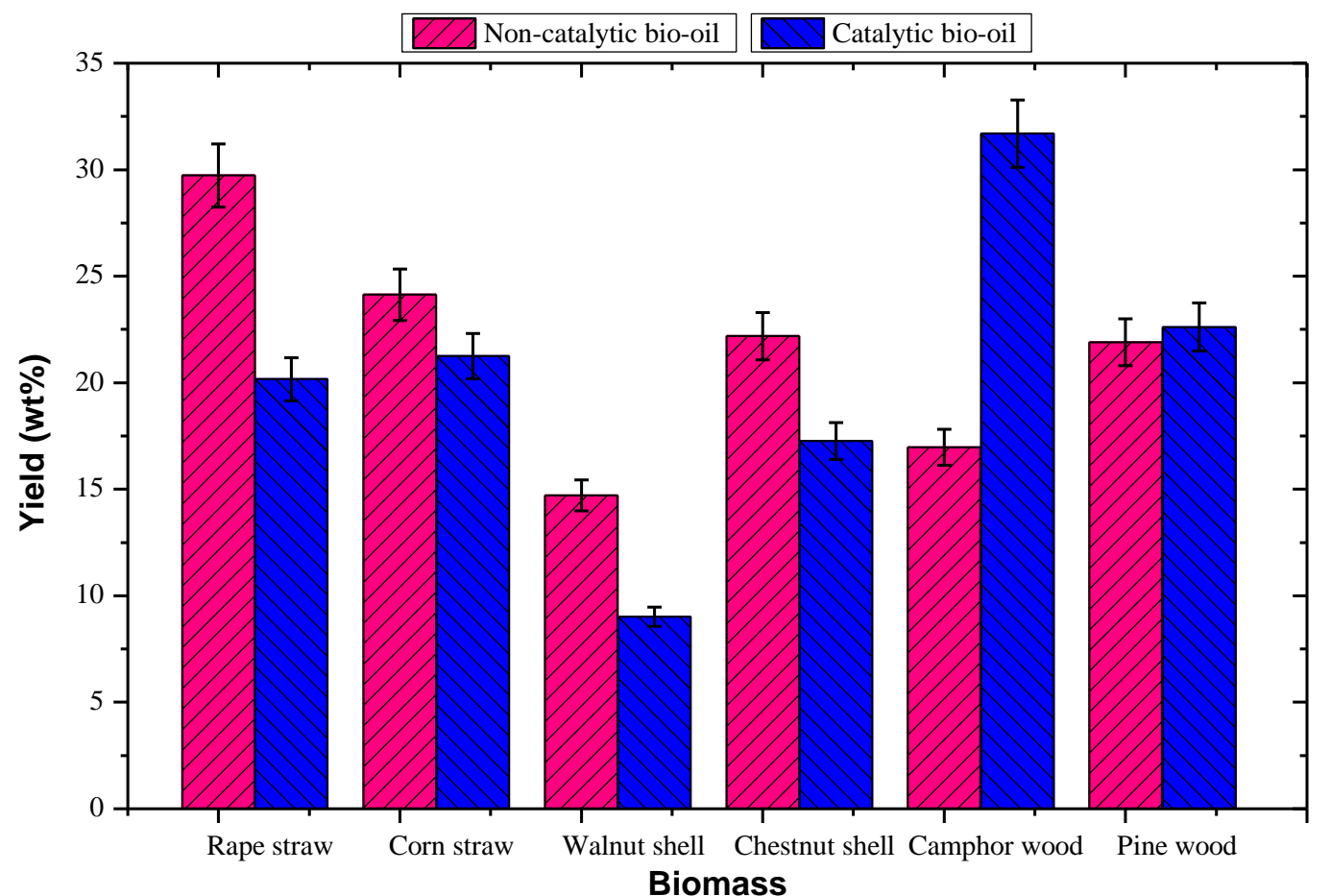

Fig. 4. Contents of aldehydes and ketones in the bio-oil obtained from six types of biomass under non-catalytic pyrolysis and catalytic pyrolysis

\section{High-value Chemicals in Bio-oil}

There are many kinds of high-value chemicals in the bio-oil. In this paper, 1hydroxy-2-butanone, propionaldehyde, 5-HMF, and $2(5 \mathrm{H})$-furanone were selected for analysis. These chemicals were selected because they had a high market value and they had a relatively high concentration in the bio-oil. Therefore, the influence of the biomass and $\mathrm{ZnCl}_{2}$ catalyst on the content of 1-hydroxy-2-butanone, propionaldehyde, 5-HMF, and $2(5 \mathrm{H})$-furanone was analyzed. The influence of different biomass types and $\mathrm{ZnCl}_{2}$ catalyst on the content of 1-hydroxy-2-butanone, propionaldehyde, 5-HMF, and 2(5H)-furanone is displayed in Fig. 5. The results showed that the content of 1-hydroxy-2-butanone were higher than propionaldehyde, $5-\mathrm{HMF}$ and $2(5 \mathrm{H})$-furanone. In the non-catalytic bio-oil, the contents of 1-hydroxy-2-butanone, 5-HMF, and $2(5 \mathrm{H})$-furanone from chestnut shell were the highest. The content of propionaldehyde derived from rape straw was the highest. The content of 1-hydroxy-2-butanone, propionaldehyde, 5-HMF, and 2(5H)-furanone from six types of biomass increased after the $\mathrm{ZnCl}_{2}$ was used as catalyst. In the catalytic bio-oil, the contents of 1-hydroxy-2-butanone and $2(5 \mathrm{H})$-furanone were the highest when derived from chestnut shell. Compared with the non-catalytic pyrolysis, the contents of 1-hydroxy-2butanone and $2(5 \mathrm{H})$-furanone in bio-oil increased $936 \%$ and $612 \%$, respectively. The contents of propionaldehyde and 5-HMF were the highest when derived from rape straw. Compared with the non-catalytic pyrolysis, the contents of propionaldehyde and 5-HMF in bio-oil increased $6.9 \%$ and $194 \%$, respectively. In catalytic bio-oil, the content of 1hydroxy-2-butanone was higher than the other three types of chemicals from six types of biomass.

The $\mathrm{ZnCl}_{2}$ catalyst played important roles on the content of 1-hydroxy-2-butanone, propionaldehyde, $5-\mathrm{HMF}$, and $2(5 \mathrm{H})$-furanon. With the effects of the catalyst, the content 
of 1-hydroxy-2-butanonein in bio-oil from camphor wood increased from $4.46 \mathrm{wt} \%$ to $46.22 \mathrm{wt} \%$, the content of 5-HMF in bio-oil from corn straw increased from $0.22 \mathrm{wt} \%$ to $1.53 \mathrm{wt} \%$, the content of propionaldehyde in bio-oil from camphor wood increased from $0.22 \mathrm{wt} \%$ to $1.08 \mathrm{wt} \%$, and the content of $2(5 \mathrm{H})$-furanone in bio-oil from camphor wood increased from $1.25 \mathrm{wt} \%$ to $3.52 \mathrm{wt} \%$. However, the content of 5-HMF from pine wood did not remarkably change. The production of 1-hydroxy-2-butanone and $2(5 \mathrm{H})$-furanone from rape straw, camphor wood, and pine wood was drastically promoted by the catalyst. The content of 1-hydroxy-2-butanone from rape straw, camphor wood, and pine wood increased by $774 \%, 1040 \%$, and $661 \%$, respectively. The content of 1-hydroxy-2-butanone from rape straw, camphor wood, and pine wood increased by $350 \%, 715 \%$, and $282 \%$, respectively. The contents of cellulose in camphor wood, rape straw, and pine wood were higher than that in corn straw, chestnut shell, and walnut shell. The productions of 1hydroxy-2-butanone and 2(5H)-furanone were derived from the cracking of cellulose during the pyrolysis process (Stefanidis et al. 2014). In addition, the contents of 1-hydroxy2butanone, $5-\mathrm{HMF}$, and $2(5 \mathrm{H})$-furanone in non-catalytic bio-oil were higher compared to the catalytic bio-oil. The result was mainly caused by the effect of $\mathrm{ZnCl}_{2}$ catalyst on lignin conversion, in which the conversions of 1-hydroxy-2butanone, 5-HMF, and 2(5H)furanone were inhibited.

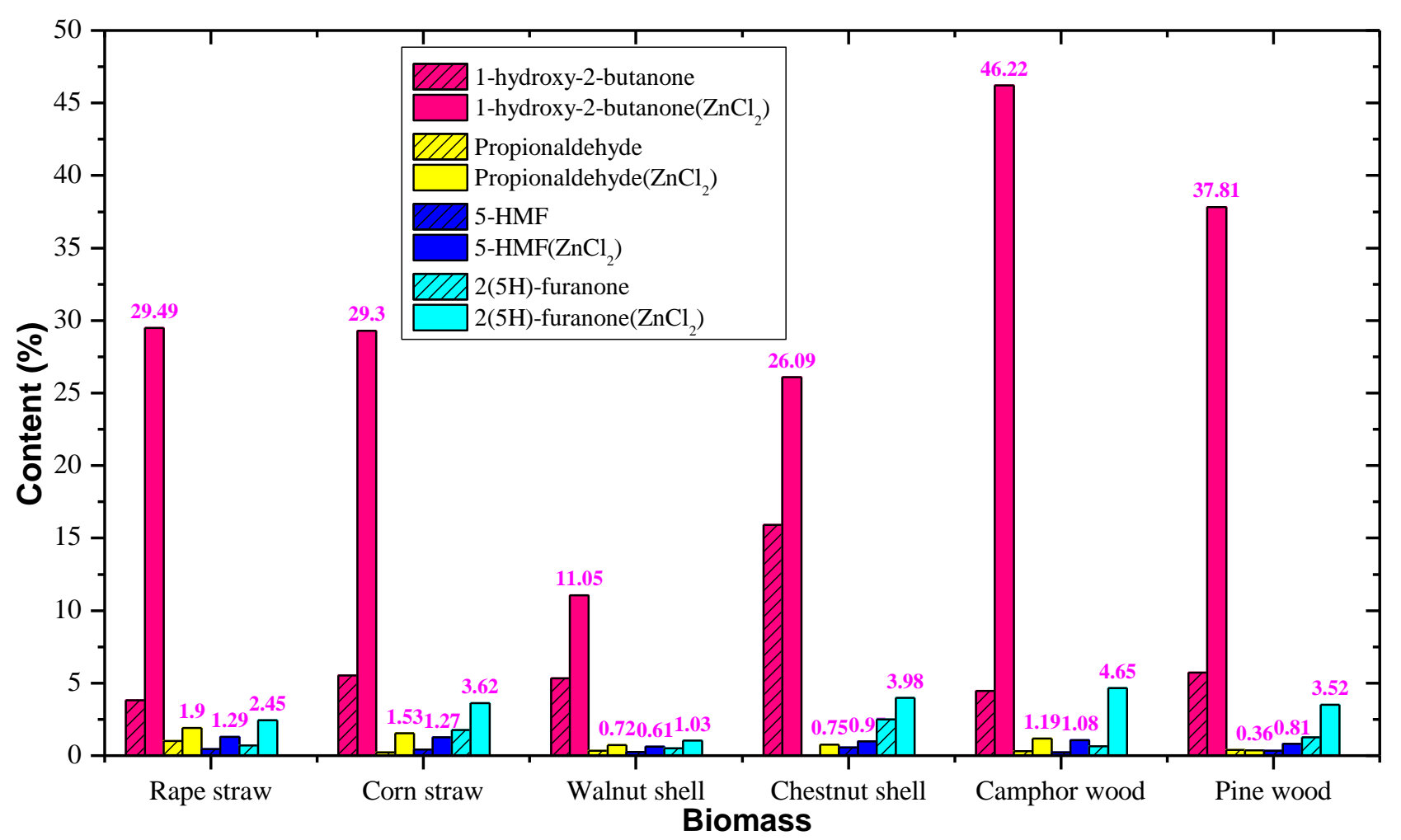

Fig. 5. Contents of 1-hydroxy-2-butanone, propionaldehyde, 5-HMF, and 2(5H)-furanone in noncatalytic and catalytic bio-oils

From the above results, it can be concluded that the contents of high-value chemicals were remarkably affected by the inclusion of a $\mathrm{ZnCl}_{2}$ catalyst during the pyrolysis of the six type of biomass (rape straw, corn straw, walnut shell, chestnut shell, camphor wood, and pine wood). The $\mathrm{ZnCl}_{2}$ catalyst had a negative effect on the yields of bio-oil from six types of biomass. Therefore, it is of great importance to use different types 
of biomass as feedstock to produce high-value chemicals, which is helpful for the industrial production of chemical compounds from renewable biomass and to realize high-value utilization of biomass.

\section{CONCLUSIONS}

1. The influence of biomass and $\mathrm{ZnCl}_{2}$ catalyst on the yields of bio-oil was analyzed. The highest bio-oil yield was from camphor wood (45.8 wt \%), while the lowest bio-oil was from chestnut shell (35.5 wt $\%)$. Additionally, the highest non-catalytic bio-char yield was from camphor wood because of its highest content of volatiles. The $\mathrm{ZnCl}_{2}$ catalyst exhibited negative roles on the yields of bio-oils. The bio-oil yields of camphor wood and pine wood were remarkably decreased by $29.0 \%$ and $14.6 \%$, respectively. In comparison with the bio-oil yields of camphor wood and pine wood, the yields of rape straw, corn straw, walnut shell, and chestnut shell were higher due to their lower content of cellulose and lignin. The $\mathrm{ZnCl}_{2}$ catalyst exhibited active roles on the yields of bio-char. The increases of bio-char yields from camphor wood and pine wood were lower than that from chestnut shell, corn straw, walnut shell, and rape straw.

2. The influence of biomass and $\mathrm{ZnCl}_{2}$ catalyst on the contents of aldehydes and ketones in bio-oils was analyzed. The contents of aldehydes and ketones in non-catalytic biooils from biomass with higher contents of holocellulose (rape straw and corn straw) were higher. The contents of aldehydes and ketones in the catalytic bio-oil of six types of biomass increased.

3. The influence of biomass and $\mathrm{ZnCl}_{2}$ catalyst on the contents of 1-hydroxy-2-butanone, propionaldehyde, $5-\mathrm{HMF}$, and $2(5 \mathrm{H})$-furanone was analyzed. In the non-catalytic and catalytic bio-oil, the contents of 1-hydroxy-2-butanone, 5-HMF, and 2(5H)-furanone from chestnut shell were the highest. The contents of 1-hydroxy-2-butanone, propionaldehyde, $5-\mathrm{HMF}$, and $2(5 \mathrm{H})$-furanone were increased because of $\mathrm{ZnCl}_{2}$. So the $\mathrm{ZnCl}_{2}$ catalyst played noticeable roles on the content of 1-hydroxy-2-butanone, propionaldehyde, $5-\mathrm{HMF}$, and $2(5 \mathrm{H})$-furanon. In the catalytic bio-oil, the contents of 1-hydroxy-2-butanone and $2(5 \mathrm{H})$-furanone were the highest from chestnut shell. Compared with the non-catalytic pyrolysis, the content of 1-hydroxy-2-butanone and $2(5 \mathrm{H})$-furanone in bio-oil increased $936 \%$ and $612 \%$, respectively. The contents of propionaldehyde and 5-HMF were the highest from rape straw. Compared with the non-catalytic pyrolysis, the content of propionaldehyde and 5-HMF in bio-oil increased $6.86 \%$ and $194 \%$, respectively.

\section{ACKNOWLEDGEMENTS}

This work was sponsored by the National Key Research and Development Program of China (No. 2019YFD1100602), the National Natural Science Foundation of China (Nos. 51606113 and 51406108), the Major Program of Natural Science Fund for Colleges and Universities in Jiangsu Province (No. 17KJA480002), and the SDUT \& Zhoucun City Integration Development Project (No. 2020ZCXCZH09). 


\section{REFERENCES CITED}

Arevalo-Gallegos, A., Ahmad, Z., Asgher, M., Parra-Saldivar, R., and Iqbal, H. M. (2017). "Lignocellulose: A sustainable material to produce value-added products with a zero waste approach-a review," Int. J. Biol. Macromol. 99, 308-318. DOI: 10.1016/j.ijbiomac.2017.02.097

Bai, X., Kim, K. H., Brown, R. C., Dalluge, E., Hutchinson, C., Lee, Y. J., and Dalluge, D. (2014). "Formation of phenolic oligomers during fast pyrolysis of lignin," Fuel 128, 170-179. DOI: 10.1016/j.fuel.2014.03.013

Bi, D. M., Li, B. Z., Liu, S. J., Yi, W. M., Jiang, M., and Lin, Z. D. (2019). "Influence of pyrolysis and torrefaction pretreatment temperature on the pyrolysis product distribution," BioResources 14(1), 1185-1197. DOI: 10.15376/biores.14.1.1185-1197

Brech, Y. L., Jia, L., Cissé, S., Mauviel, G., Brosse, N., and Dufour, A. (2016). "Mechanisms of biomass pyrolysis studied by combining a fixed bed reactor with advanced gas analysis," J. Anal. Appl. Pyrol. 117, 334-346. DOI: 10.1016/j.jaap.2015.10.013

Chwist, M., Szwaja, S., Grab-Rogaliński, K., and Pyrc, M. (2017). "Bio-oil blended butanol as a fuel to the spark ignition internal combustion reciprocating engine," Combustion Engines 169(2), 93-96. DOI: 10.19206/CE-2017-216

Climent, M. J., Corma, A., and Iborra, S. (2014). "Conversion of biomass platform molecules into fuel additives and liquid hydrocarbon fuels," Green Chem. 16(2), 516547. DOI: 10.1039/C3GC41492B

Günther, A., Huth, V., Jurasinski, G., and Glatzel, S. (2015). "The effect of biomass harvesting on greenhouse gas emissions from a rewetted temperate fen," $G C B$ Bioenergy 7(5), 1092-1106. DOI: 10.1111/gcbb.12214

Hernando, H., Ochoa-Hernández, C., Shamzhy, M., Moreno, I., Fermoso, J., Pizarro, P., Coronado, J. M., Čejka, J., and Serrano, D. P. (2019). "The crucial role of clay binders in the performance of ZSM-5 based materials for biomass catalytic pyrolysis," Catal. Sci. Tech. 9(3), 789-802. DOI: 10.1039/c8cy02116c

$\mathrm{Hu}$, J., Shen, D., Wu, S., and Xiao, R. (2017). "Insight into the effect of $\mathrm{ZnCl}_{2}$ on analytical pyrolysis behavior of cellulolytic enzyme corn stover lignin," J. Anal. Appl. Pyrol. 127, 444-450. DOI: 10.1016/j.jaap.2017.07.005

Ito, R., Miyafuji, H., Miyazaki, Y., and Kawai, T. (2016). "Production of 5hydroxymethylfurfural from wood by ionic liquid treatment," J. Wood Sci. 62(4), 349-355. DOI: 10.1007/s10086-016-1554-7

Kabir, G., and Hameed, B. H. (2017). "Recent progress on catalytic pyrolysis of lignocellulosic biomass to high-grade bio-oil and bio-chemicals," Renew. Sustain. Energy Rev. 70, 945-967. DOI: 10.1016/j.rser.2016.12.001

Kan, T., Sun, X., Wang, H., Li, C., and Muhammad, U. (2012). "Production of gasoline and diesel from coal tar via its catalytic hydrogenation in serial fixed beds," Energ. Fuel 26(6), 3604-3611. DOI: 10.1021/ef3004398

Knaggs, M., Ramsey, J., Unione, A., Harkreader, D., Oelfke, J., Keairns, D., and Bender, W. (2015). "Application of systems readiness level methods in advanced fossil energy applications," Procedia Comput. Sci. 44, 497-506. DOI: 10.1016/j.procs.2015.03.071

Krivtcova, N. I., Tataurshikov, A. A., Ivanchina, E. D., and Krivtsov, E. B. (2015). "Mathematical modelling of diesel fuel hydrodesulfurization kinetics," Procedia. Chem. 15, 180-186. DOI: 10.1016/j.proche.2015.10.029 
Laino, T., Tuma, C., Moor, P., Martin, E., Stolz, S., and Curioni, A. (2012).

"Mechanisms of propylene glycol and triacetin pyrolysis," J. Phys. Chem. A 116(18), 4602-4609. DOI: 10.1021/jp300997d

Lazzari, E., Schena, T., Primaz, C. T., Da Silva Maciel, G. P., Machado, M. E., Cardoso, C. A. L., Jacques, R. A., and Caramão, E. B. (2016). "Production and chromategraphic characterization of bio-oil from the pyrolysis of mango seed waste," Ind. Crop. Prod. 83, 529-536. DOI: 10.1016/j.indcrop.2015.12.073

Lédé, J. (2012). "Cellulose pyrolysis kinetics: An historical review on the existence and role of intermediate active cellulose," J. Anal. Appl. Pyrol. 94, 17-32. DOI: 10.1016/j.jaap.2011.12.019

Li, Z. X., Han, T. Z., Guo, W. X., and Wang, G. M. (2013). "The comparison of different preparation methods of catalysts for furfural hydrogenization to 2-methyl furan," $A d v$. Mater. Res. (791-793), 68-71. DOI: 10.4028/www.scientific.net/amr.791-793.68

Li, X., Wan, W., Kattel, S., Chen, J. G., and Wang, T. (2016). "Selective hydrogenation of biomass-derived 2(5H)-furanone over Pt-Ni and Pt-Co bimetallic catalysts: From model surfaces to supported catalysts," J. Catal. 344, 148-156. DOI: 10.1016/j.jcat.2016.09.027

Li, Y. Y., Sun, X. D., Dong, X. Y. M., Wang, Y., and Zhu, J. H. (2017). “Acquiring an efficient warm- $\mathrm{CO}_{2}$ sorbent from advanced pyrolysis of magnesium oxalate," ChemNanoMat 3(11), 822-832. DOI: 10.1002/cnma.201700183

Li, X., Lei, T., Wang, Z., Li, X. Y., Wen, M. Y., Yang, M., Chen, G. F., He, X. F., Xu, H. Y., Guan, Q., et al. (2018). "Catalytic pyrolysis of corn straw with magnetic solid acid catalyst to prepare levulinic acid by response surface methodology," Ind. Crop. Prod. 116, 73-80. DOI: 10.1016/j.indcrop.2018.02.049

Liu, Y. R., Nie, Y., Lu, X. M., Zhang, X. P., He, H. Y., Pan, F. J., Zhou, L., Liu, X., Ji, X. Y., and Zhang, S. J. (2019). "Cascade utilization of lignocellulosic biomass to high-value products," Green Chem. 221(13), 3499-3535. DOI: 10.1039/C9GC00473D

Lu, Q., Dong, C.-Q., Zhang, X.-M., Tian, H.-Y., Yang, Y.-P., and Zhu, X.-F. (2011). "Selective fast pyrolysis of biomass impregnated with $\mathrm{ZnCl}_{2}$ to produce furfural: Analytical Py-GC/MS study," J. Anal. Appl. Pyrol. 90(2), 204-212. DOI: 10.1016/j.jaap.2010.12.007

Magdalena, J. A., Tomás-Pejó, E., Ballesteros, M., and González-Fernandez, C. (2018). "Volatile fatty acids production from protease pretreated Chlorella biomass via anaerobic digestion," Biotechnol. Progr. 34(6), 1363-1369. DOI: 10.1002/btpr.2696

Néstor, T., Gabús, M., Yoshida, M. I., and Suárez, A. C. (2016). “Thermal study of wood impregnated with $\mathrm{ZnCl}_{2}$," Eur. J. Wood. Wood. Prod. 75, 633-638. DOI: 10.1007/s00107-016-1113-3

Paine, III, J. B., Pithawalla, Y. B., and Naworal, J. D. (2008). "Carbohydrate pyrolysis mechanisms from isotopic labeling: Part 4. The pyrolysis of d-glucose: The formation of furans," J. Anal. Appl. Pyrol. 83(1), 37-63. DOI: 10.1016/j.jaap.2008.05.008

Penmetsa, V. K., and Steele, P. H. (2012). "Preliminary findings for the production of water repellent torrefied wood pellets with pyrolysis oil," Environ. Prog. Sustain. 31(2), 235-239. DOI: 10.1002/ep.11624

Qu, T., Guo, W., Shen, L., Xiao, J., and Zhao, K. (2011). "Experimental study of biomass pyrolysis based on three major components: Hemicellulose, cellulose, and lignin," Ind. Eng. Chem. Res. 50(18), 10424-10433. DOI: 10.1021/ie1025453 
Rossi, R., Lessi, M., Manzini, C., Marianetti, G., and Bellina, F. (2017). "Synthesis and biological properties of $2(5 \mathrm{H})$-furanones featuring bromine atoms on the heterocyclic ring and/or brominated substituents," Curr. Org. Chem. 21(11), 964-1018. DOI: $10.2174 / 1385272821666170111151917$

Sharma, A., Pareek, V., and Zhang, D. (2015). "Biomass pyrolysis-A review of modelling, process parameters and catalytic studies," Renew. Sustain. Energy Rev. 50, 1081-1096. DOI: 10.1002/chin.201609249

Shen, D., Jin, W., Hu, J., Xiao, R., and Luo, K. (2015). “An overview on fast pyrolysis of the main constituents in lignocellulosic biomass to valued-added chemicals: Structures, pathways and interactions," Renew. Sustain. Energy Rev. 51, 761-774. DOI: 10.1002/chin.201606275

Sovacool, B. K., Heffron, R. J., McCauley, D., and Goldthau, A. (2016). "Energy decisions reframed as justice and ethical concerns," Nature Energy 1(5), 1-23. DOI: 10.1038/nenergy.2016.24

Stefanidis, S. D., Kalogiannis, K. G., Iliopoulou, E. F., Michailof, C. M., Pilavachi, P. A., and Lappas, A. A. (2014). "A study of lignocellulosic biomass pyrolysis via the pyrolysis of cellulose, hemicellulose and lignin," J. Anal. Appl. Pyrol. 105, 143-150. DOI: 10.1016/j.jaap.2013.10.013

Wang, J., Bi, P., Zhang, Y., Xue, H., Jiang, P., Wu, X., Liu, J., Wang, T., and Li, Q. (2015). "Preparation of jet fuel range hydrocarbons by catalytic transformation of biooil derived from fast pyrolysis of straw stalk," Energy 86, 488-499. DOI: 10.1016/j.energy.2015.04.053

Wang, F., Zheng, Y., Huang, Y., Yang, X., Liu, C., Xu, G., and Zheng, Z. (2016). "Component analysis of pyrolysis bio-oil from three major components of biomass and Pinus yunnanensis by ZSM-5 catalytic," Transactions of the Chinese Society of Agricultural Engineering 32, 331-337. DOI: 10.11975/j.issn.1002-6819.2016.z2.047

Wang, H., Zhu, C., Liu, Q., Tan, J., Wang, C., Liang, Z., and Ma, L. (2019). "Cover feature: Selective conversion of cellulose to hydroxyacetone and 1-hydroxy-2butanone with Sn-Ni bimetallic catalysts," ChemSusChem 12(10), 2154-2160. DOI: 10.1002/cssc.201901216

Ye, X. N., Lu, Q., Wang, X., Wang, T. P., Guo, H. Q., Cui, M. S., Dong, C.-Q., and Yang, Y. P. (2019). "Fast pyrolysis of corn stalks at different growth stages to selectively produce 4-vinyl phenol and 5-hydroxymethyl furfural," Waste Biomass Valori. 10, 3867-3878. DOI: 10.1007/s12649-018-0259-0

Zabelkin, S., Bikbulatova, G., Grachev, A., Bashkirov, V., Burenkov, S., and Makarov, A. A. (2019). "Modification of bitumen binder by the liquid products of wood fast pyrolysis," Road Mater. Pavement 20(5), 1182-1200. DOI: 10.1080/14680629.2018.1439765

Zelelew, H., Paugh, C., Corrigan, M., Belagutti, S., and Ramakrishnareddy, J. (2013). "Laboratory evaluation of the mechanical properties of plant-produced warm-mix asphalt mixtures," Road Mater. Pav. 14(1), 49-70. DOI: 10.1080/14680629.2012.735799

Zhang, J., Wang, Y. H., Qu, Y. S., Wei, Q. Y., Li, H. Q. (2018). "Effect of the organizational difference of corn stalk on hemicellulose extraction and enzymatic hydrolysis," Ind. Crop. Prod. 112:698-704. DOI: 10.1016/j.indcrop.2018.01.007

Zheng, M., Wang, Z., Li, X., Qiao, X., Song, W., and Guo, L. (2016). "Initial reaction mechanisms of cellulose pyrolysis revealed by ReaxFF molecular dynamics," Fuel 177, 130-141. DOI: 10.1016/j.fuel.2016.03.008 
Zhou, X. X., and Feng, C. (2017). "The impact of environmental regulation on fossil energy consumption in China: Direct and indirect effects," J. Clean. Prod. 142 (Part 4), 3174-3183. DOI: 10.1016/j.jclepro.2016.10.152

Article submitted: March 4, 2020; Peer review completed: April 26, 2020; Revised version received and accepted: May 28, 2020; Published: June 2, 2020.

DOI: $10.15376 /$ biores. 15.3.5666-5678 